\title{
Electrical Imaging Techniques for Environmental and Engineering Applications
}

Torleif Dahlin, Dept. of Engineeering Geology, Lund University, Box 118, S-221 00 Lund, Sweden

Copyright 2004, SBGf - Sociedade Brasileira de Geofísica

Este texto foi preparado para a apresentação no I Simpósio Regional da Sociedade Brasileira de Geofísica, São Paulo, 26-28 de setembro de 2004. Seu conteúdo fol revisado pela Comissão Tecno-científica do I SR-SBGf mas não necessariamente representa a opinião da SBGf ou de seus associados. E proibida a reprodução total ou parcial deste material para propósitos comerciais sem prévia autorização da SBGf.

\section{Abstract}

The development of electrical resistivity imaging techniques has been rapid in the last decade. This applies to data acquisition as well as inverse modelling techniques, and has lead to a greatly expanded practical applicability of the method. A trend today is to move from traditionally used electrode array types towards nonconventional arrays that are more efficient for multielectrode equipment with multi-channel measuring capability, e.g. multiple gradient array measurements. On the data processing and analysis side robust (L1-norm type) inversion and time-lapse inversion can be mentioned as valuable tools.

Resistivity imaging is now becoming widely used in environmental and engineering applications where increased knowledge about the subsurface is sought. Important applications include of groundwater resources mapping and vulnerability studies, contaminant mapping and monitoring, geotechnical pre-investigation, natural resources prospecting, geothermal prospecting, permafrost mapping, leakage detection etc.. Selected examples will be presented.

Good quality induced polarisation imaging, using data acquisition equipment that is primarily designed for resistivity imaging, has proved to be feasible on a time and cost efficient basis in some environments. In other environments data quality problems will occur with such equipment in standard configuration. A prime application for IP imaging appears to be mapping and characterisation of buried waste, which is expected to become increasingly important for rehabilitation and re use of areas used as landfills.

\section{Introduction}

Over the past few decades growing populations have increased the pressure on natural resources, raising demands for water supply, housing and infrastructure. This pressure can be expected to rise, and combined with environmental stress caused by pollution, there is a growing need for detailed geological studies connected to environmental protection and infrastructure development. Geophysical methods can play an important role in these studies, where DC (direct current) resistivity imaging is one of the methods of primary interest. This paper gives a short introduction to DC resistivity imaging, and it includes short descriptions of the procedures used for data acquisition, the methods used to process data and how resistivity images are constructed and interpreted. A few field examples are presented to illustrate the applicability of the method.

\section{Electrical Imaging}

The resistivity method is based on measuring the potentials between one electrode pair while transmitting direct current (DC) between another electrode pair. The depth of penetration is proportional to the separation between the electrodes, in homogeneous ground, and varying the electrode separation provides information about the stratification of the ground. The measured quantity is called apparent resistivity. Interpreting the resistivity data consists of two steps: a physical interpretation of the measured data, resulting in a physical model, and then a geological interpretation of the resulting physical parameters. The advent of automated data acquisition and inversion in recent years has increased the practical applicability of resistivity imaging tremendously. The method is now widely used in groundwater and environmental application in some countries (e.g. Denmark).

Two-dimensional (2D) resistivity imaging requires data to be recorded with many different electrode separations along a line. It is important to have a dense enough data cover laterally and in terms of electrode separations to recover complex structures in the ground (e.g. Griffiths and Barker 1993; Dahlin and Loke 1998), which demands the use of automated multi-electrode data acquisition systems to be practical. Computer controlled data acquisition systems generally consist of a resistivity instrument, a relay-switching unit, a computer, electrode cables, various connectors and electrodes (e.g. Overmeeren and Ritsema 1988; Griffiths et al. 1990; Dahlin 1993). In field surveying the electrode cables are rolled out and electrodes connected to it, after which the data acquisition software automatically checks the electrode contact and scans through a pre-defined measurement protocol. Extension of the line is achieved through a roll-along technique, in which part of the layout is shifted for example a quarter of the total layout length and new measurements are added. An alternative approach for automated data acquisition is the pulled array in which a cable with a number of electrodes is used, where one electrode pair is used for transmitting current while measuring the potentials over several electrode pairs (e.g. Christensen and Sørensen 1998). The advantage of this concept is a possibility of high speed of surveying and high lateral resolution, but demands on open even terrain and limited depth cover for logistical reasons.

The large amounts of data produced by multi electrode systems require automated data handling and processing. Automatic inverse numerical modelling techniques 
(inversion) based on the finite difference or finite element methods for the forward calculations have developed in response to this need (e.g. Oldenburg and Li 1994; Tsourlos 1995; Loke and Barker 1996). In these the subsurface is normally divided in cells of fixed dimensions, the cell size increasing with depth, for which the resistivities are adjusted iteratively until an acceptable agreement between the input data and the model responses is reached.

Resistivity imaging may also be expanded by including measuring time-domain induced polarasation (IP). Good quality IP imaging, using data acquisition equipment that is primarily designed for resistivity imaging, has proved to be feasible on a time and cost efficient basis in some environments. In other environments data quality problems will occur with such equipment in standard configuration. (Dahlin et al 2002; Leroux and Dahlin 2003)

A few examples from different fields of application are presented below. In all examples the ABEM Lund Imaging System (Dahlin 1996) was used for the data acquisition. The data was processed by means of inverse numerical modelling using Res2dinv (for all presented examples with the $L_{1}$-norm or robust inversion option) and plotted as depth sections.

\section{Example: Aquifer Mapping and Recharge Studies at Nyamandhlovu-Sawmills, Zimbabwe}

The Karoo sandstone aquifer has, since 1970, been commercially exploited around the town of Nyamandhlovu for irrigation, and in recent years, the aquifer has been considered as a possible additional water source for the city of Bulawayo. Studies on the recharge to the aquifer are now required in order to ensure that the aquifer is not over-exploited and that a sustainable abstraction rate is maintained. The rate of recharge to the Karoo aquifer is an important parameter, which will control the optimum rate of groundwater abstraction from the basin. The two critical factors controlling recharge are 1) the rate of direct recharge by infiltration and percolation into the aquifer system, and 2) the areal extent of over which recharge takes place.

Among other methods, a variety of geophysical investigation methods (resistivity, TEM, gravity, HLEM and ground and aerial magnetic surveys) have been used in the study area to try and determine the aquifer geometry. A key method has been multi-electrode resistivity imaging. This method has been used around Sawmills and around Nyamandhlovu (Dahlin et al. 1999, Gwaze et al. 2000).

a)

b)
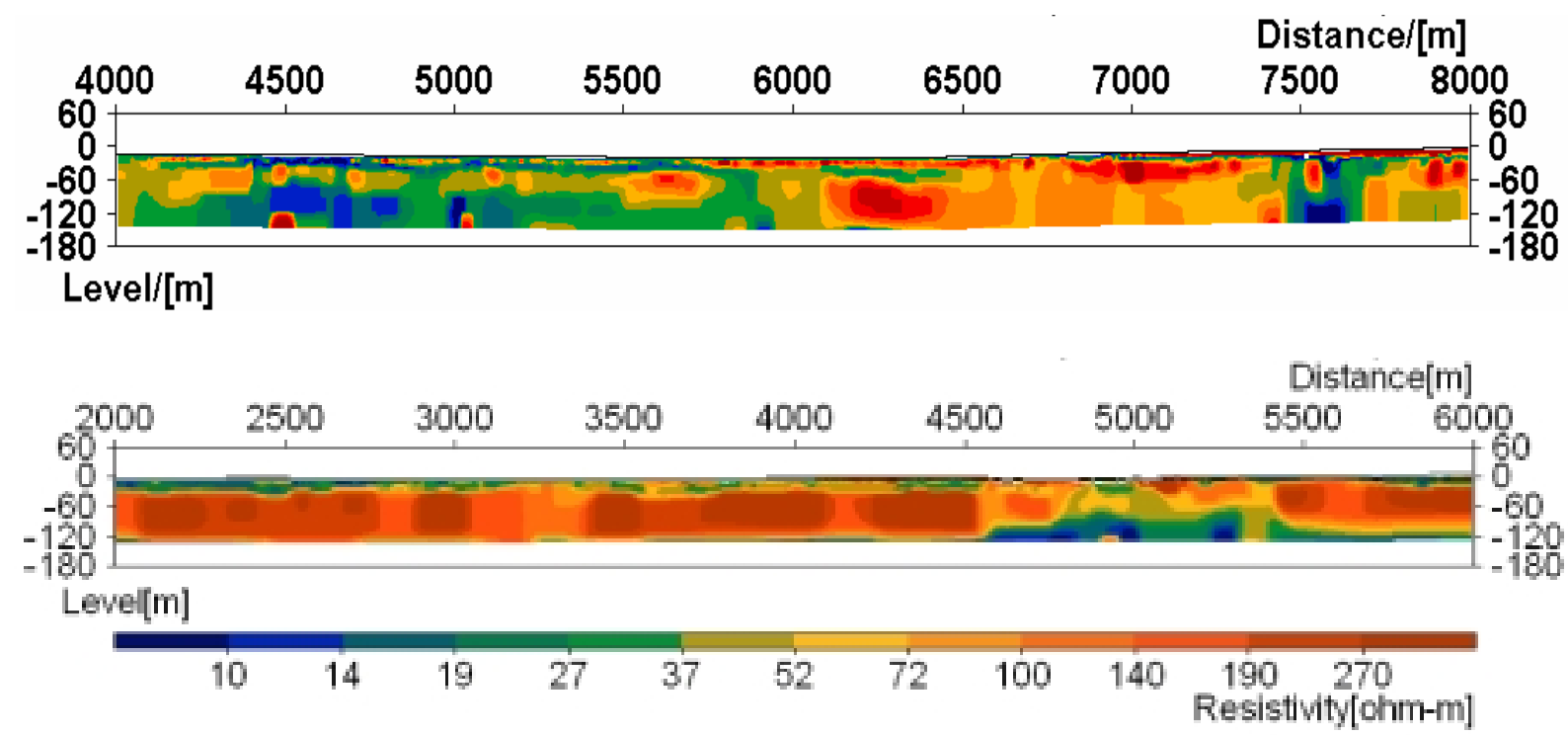

Figure 1. Parts of two $10 \mathrm{~km}$ long profiles presented as inverted resistivity sections, from a) Epping Forest (upper) and b) Sawmills (lower), Zimbabwe.

Some results are presented here which focus on the Karoo basalt and allow an appreciation of the changing nature of the basalt layer and its probable effect on the groundwater conditions. Two profiles are presented: the first is from the south-eastern part of the study area near the basin margin (Epping Forest line 1); the second (Sawmills line 2) is from the north-western part of the study area much further into the Karoo basin, near Sawmills.
The first of these two sections (Figure 1a) shows that the basalt near the basin margin is thin, deeply weathered and fractured. It is therefore likely to be permeable and the sandstone aquifer underneath the basalt in such areas is likely to be unconfined and receive direct recharge. The second section (Figure $1 \mathrm{~b}$ ) further from the basin margins shows that the basalt has become thicker, continuous and relatively fresh, although with some fractured/faulted zones such as the anomalous zone at $5000 \mathrm{~m}$. This zone coincides with the location of three 
deep boreholes documented by MacDonald (1970), and the basalt thicknesses suggested by the inverted model matches the drilling data well. In such localities, the basalt is likely to be impermeable and act as a confining layer. This interpretation of the geophysical evidence is supported by the presence of artesian wells at Sawmills and further into the basin and by the chemical and isotopic data collected from boreholes in the basin. (Larsen et al. 2001).

\section{Example: Saltwater Infiltration in an Aquifer in Southern Sweden}

Five intersecting resistivity sections were measured in glaciofluvial deposits hosting an aquifer of regional importance situated along a heavily trafficked road at Bergaåsen near Ljungby in southern Sweden. The winter salt spreading has caused a regular salinity increase throughout the years and the aim of the study was to image the infiltration of saltwater in the aquifer. For that purpose, the sections were measured exactly at the same location before and after the winter and interpreted using a time-lapse inverse procedure. Auger drilling and RCPT data were also available for correlation. After the winter, the resistivity had generally decreased under the water table and increased above it Figure 2]. The decrease in resistivity in the saturated zone is interpreted as a plume of more saline groundwater created by de-icing salt from the road, which is transported in the downstream direction. The increase in the upper layer can be explained by changes in temperature and soil moisture. The study shows that time-lapse resistivity investigations has potential for imaging hydraulic pathways in complex hydrogeological environments, but it should preferably be done with a higher temporal resolution. Also, different materials respond differently to changes in salinity, temperature and water content, and that should, when possible, be taken into account. (Dahlin et al 2004)

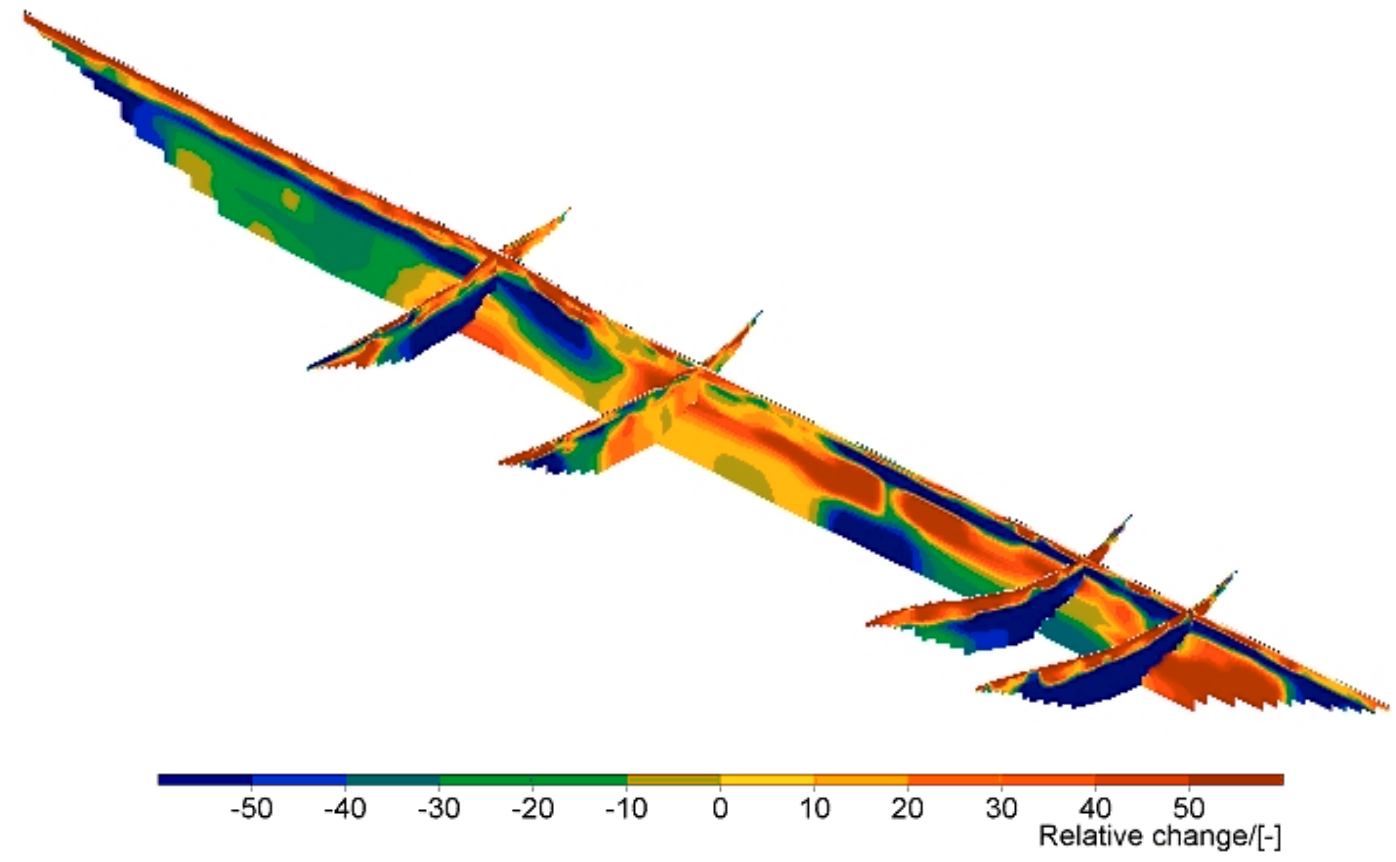

Figure 2. Gathered sections of relative difference between lines measured in April 2002 and October 2001 (view from SW). The long profile is $400 \mathrm{~m}$ and the cross profiles are $80 \mathrm{~m}$ long, with maximum inverted model depth around $25 \mathrm{~m}$.

\section{Example: Landfill Restoration Project in Southern Sweden}

A resistivity and time-domain induced polarisation survey was conducted at a landfill site under restoration at Härlöv in Southern Sweden (Svensson et al 2004). The covering of the landfill had begun some years ago, without keeping precise trace of the work done, as is usual in such procedures. The survey was conducted in two steps, on two adjacent areas. First, a partly covered area (part 1) that had been investigated by auger drilling was covered by a number of geoelectrical sections, in order to help planning continuing work. Then, a second area (part 2) that should have received its final cover was imaged, and some defects in the cover could be detected and repaired. The resistivity and time-domain induced polarisation results were consistent with the geotechnical drillings, and they enabled quasi-continuous mapping along the profiles. 3D-visualisation showed the overall consistency of the 2D lines and helped getting a global view of the site. In spite of some ambiguities, cover and waste could be distinguished in most cases. Especially, fine-grained cover material could be clearly distinguished from the rest. 
a)

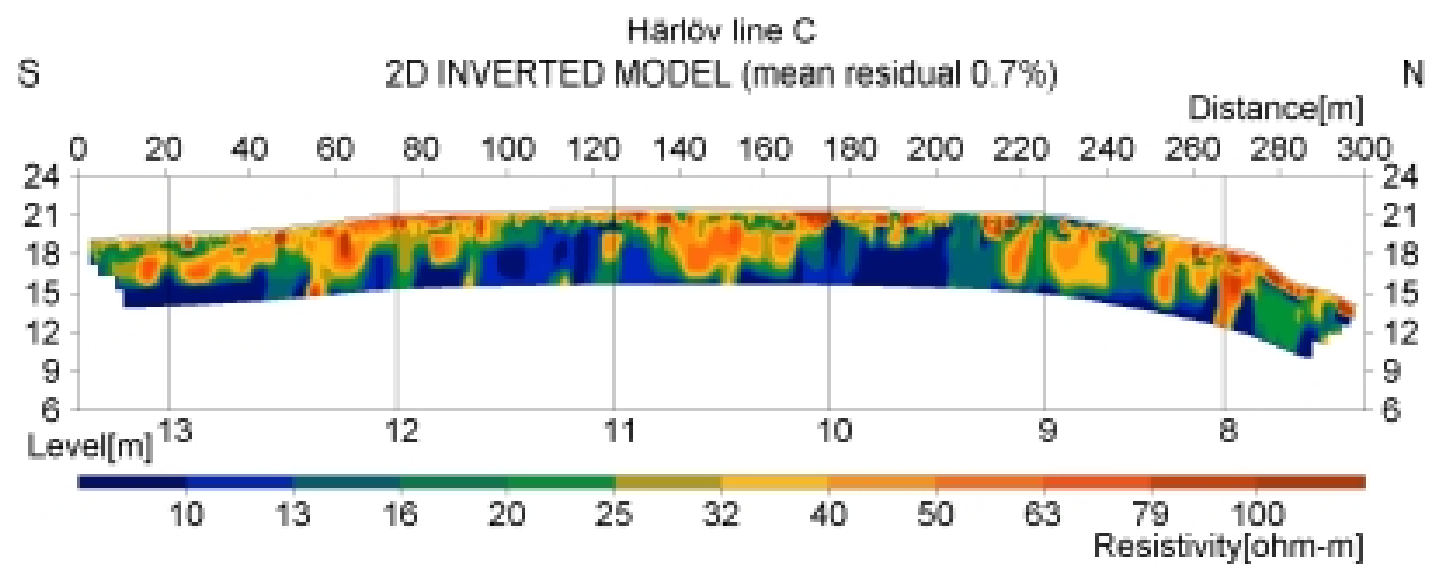

b)

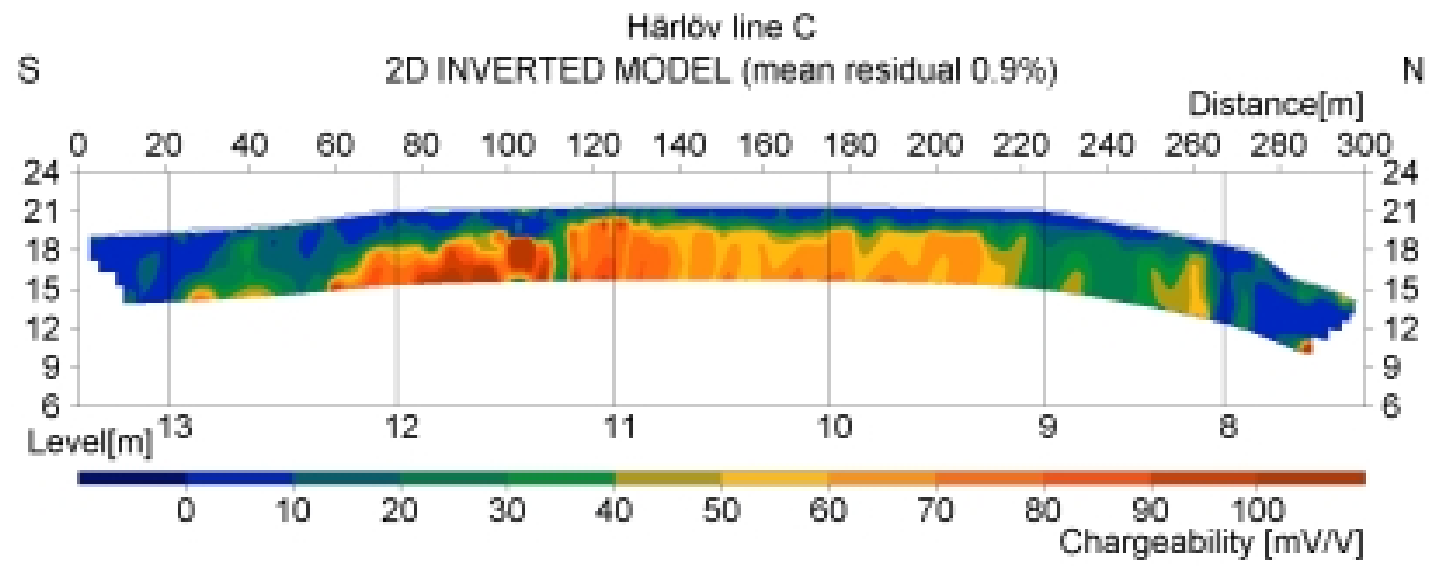

Figure 3. Inverted sections for part 1, line C at Härlöv a) resistivity, and b) IP (chargeability, 20 to $120 \mathrm{~ms}$ ).

a)

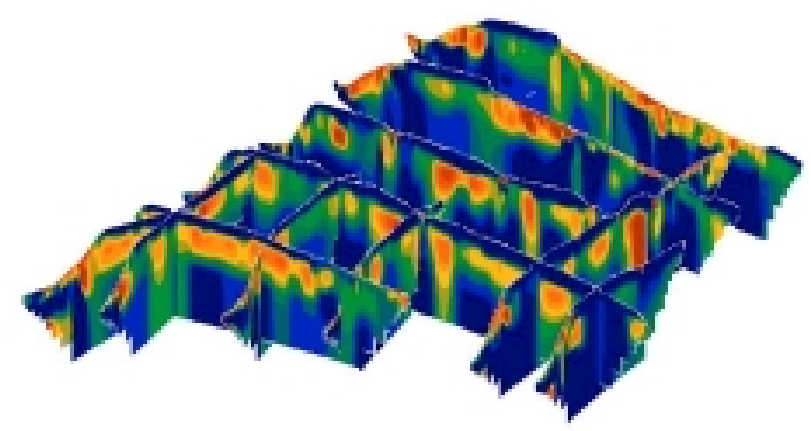

b)

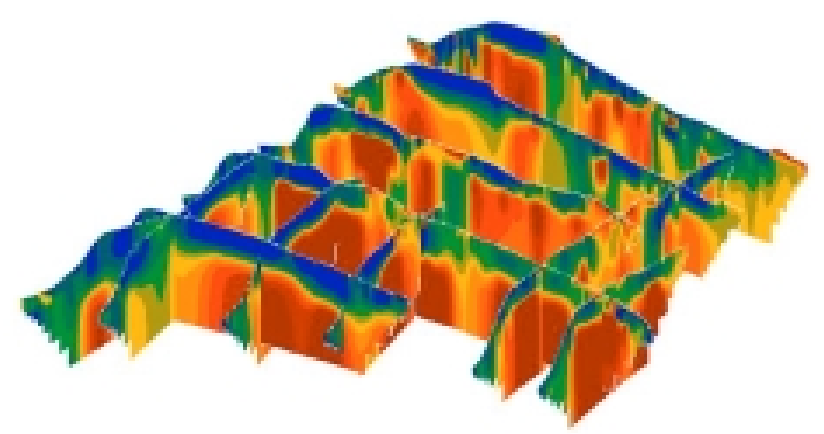

Figure 4. Inverted sections for part 2 at Härlöv a) resistivity b) IP (chargeability, 10-110ms). Same resistivity and chargeability scale as in Figure 3 used. 
On most of the lines, a first inhomogeneous layer with higher resistivity can be seen, overlying a rather conductive material, with resistivity value most often below $10 \Omega \mathrm{m}$, as shown by example in Figure 3. The inverted induced polarisation sections show a reversed picture, with a first layer with low chargeability values over a highly chargeable background with values over $50 \mathrm{mV} / \mathrm{V}$ (Figure 3). Six geotechnical auger drillings have been placed on this line. The high chargeability values correlate well with the distribution of the waste. Small discrepancies at couple of points could be due to lateral effects, limitations in the drilling documentation or uncertainty in the relative locations of auger drillings and resistivity lines. The inhomogeneity in the material is very high in all three space directions.

In another part of the landfill the continuity of low resistive clayey cover material could easily be identified with the resistivity results Figure 4, and parts where clay cover was missing could be identified.

\section{Discussion and Conclusions}

Electrical imaging can be a powerful tool for environmental and engineering investigations. In groundwater applications the potential of delineating aquifers and their boundary conditions, and outlining zones of increased recharge potential and vulnerability, is demonstrated by the examples above. In engineering geology investigations the extent of different soil layers, mapping variations in depth to bedrock, and indentification and delineation of fractured and weathered zones in the rock are key issues where the technique has proven useful.

The 3D extent of buried waste and the distribution of pollution in the ground and groundwater can also be mapped successfully. In particular for buried waste applications the combined measurement of resistivity and chargeability (IP-effect) has proved to have added value.

Analysis of resistivity sections measured on the same electrode layout, at different points in time, has shown potential for mapping migration of contaminants and imaging hydraulic pathsways.

Geophysical results as exemplified above should never be used alone, but need support and verification from other methods. Resistivity imaging can on the other hand form an excellent basis for e.g. a drilling and sampling programme, and be a means of providing an overview of an area, which is impractical with drilling alone.

The advantages can be summarised as:

- Good geological overview, with delineation of zones that are likely to have different hydraulic properties.

- Continuous data cover.

- Excellent basis for drilling and sampling programmes as well as other follow-up investigations.
- Rather small sensitivity to noise, from e.g. electromagnetic disturbances.

- Works in low resistive environments as well as high resistive environments.

- Relatively low cost.

There are some limitations of the technique, which may be severe under certain circumstances, but of less importance in most cases. The major limitations are:

- Long layouts needed for large depth penetration.

- Ambiguity of geophysical interpretation due to the principles of equivalence and suppression, and so called "3D effects" in cases with strong variation perpendicular to the lines of investigation.

- Ambiguity in geological interpretation due to non-unique resistivity signatures of the investigated materials.

- Galvanic contact is required, which can be time consuming to arrange and be a problem for example in areas with dry or frozen ground, and rock outcrops.

- Possible disturbance from conductive objects in galvanic contact with the ground, such as pipes, grounded metal fences etc..

On-going and future developments include techniques for combined data acquisition and inversion with other geophysical parameters, which is a way ahead in order to achieve more comprehensive and reliable models of the underground. The ultimate goal would be to develop tools for three-dimensional mapping of e.g. the hydraulic properties of the ground through the combination of different types of geophysical and non-geophysical data. A promising step in this direction appears to be to include induced polarisation (IP) in the resistivity imaging data acquisition at limited extra cost. However, with present equipment this is only feasible for favourable site conditions. Hence there is scope for development of novel instruments and data processing techniques to make it possible in a wider range of environments.

\section{Acknowledgements}

The geophysical investigations within the Karoo aquifer project presented above were done in co operation between the University of Zimbabwe in Harare and the University of Lund in Sweden, and the field data have been collected through MSc studies. The project was funded by Sida/SAREC.

Virginie Leroux worked up and analysed the Bergaåsen data which was provided by Scandiaconsult, the Road Administration of Sweden and Mark och Vatten Ingenjörerna AB.

Kristianstads Kommun financed the field survey at Härlöv carried out in fruitful cooperation with Tyréns AB. Åke och Greta Lissheds Stiftelse and Swedish Association of Graduate Engineers (Civilingenjörsförbundets Miljöfond) funded the research and development work that paved 
the way for the efficient survey at this site. Virginie Leroux worked up and analysed the results also for this site.

The work by Virginie Leroux was partly financed by a European Commission Marie Curie grant, contract number NoEVK1-CT-2000-50004.

\section{References}

Christensen, N.B. and Sørensen, K.I. (1998) Surface and borehole electric and electromagnetic methods for hydrogeological investigations, European Journal of Engineering and Environmental Geophysics, 3(1), 75-90.

Dahlin, T. (1993) On the Automation of 2D Resistivity Surveying for Engineering and Environmental Applications, Dr.Thesis, ISRN LUTVDG/TVDG--1007-SE, ISBN 91-628-1032-4, Lund University, 187p.

Dahlin, T. (1996) 2D resistivity surveying for environmental and engineering applications, First Break, 14(7), 275-283.

Dahlin, T. and Loke, M.H. (1998) Resolution of 2D Wenner resistivity imaging as assessed by numerical modelling, Journal of Applied Geophysics, 38(4), p. 237249.

Dahlin, T., Glatz, D., Persson, N., Gwaze, P. and Owen, R. (1999) Electrical and Magnetic Investigations of Deep Aquifers in North Matabeleland, Zimbabwe, Procs. 5th Meeting Environmental and Engineering Geophysics, Budapest, 5-9 September 1999, 2p.

Dahlin, T., Leroux, V. and Nissen, J. (2002) Measuring Techniques in Induced Polarisation Imaging, Journal of Applied Geophysics, 50(3), 279-298.

Griffiths, D.H., Turnbull, J. and Olayinka, A.I. (1990) Twodimensional resistivity mapping with a computercontrolled array, First Break, 8(4), 121-129.

Griffiths, D.H. and Barker, R.D. (1993) Two-dimensional resistivity imaging and modelling in areas of complex geology, Journal of Applied Geophysics, vol 29, p 211226.

Gwaze, P., Dahlin, T., Owen, R., Gwavava, O. and Danielsen, J. (2000) Geophysical Investigations of the Karoo Aquifer at Nyamandhlovu, Zimbabwe, Procs. 6th Meeting of the European Association for Environmental and Engineering Geophysics, 3-7 September 2000, Bochum, 4p.

Larsen, F., Owen, R., Dahlin, T. and Mangeya. P. (2001) A preliminary analysis of the groundwater recharge to the Karoo formations, mid-Zambezi basin, Zimbabwe. in Procs. 2nd WaterNet/Warfsa Symposium. Integrated Water Resources Management: Theory, Practice, Cases. Cape Town, RSA. 30-31 Oct 2001.

Leroux V. and Dahlin T. (2003) Site conditions requiring extra precautions for induced polarisation measurements, Procs. 9th Meeting Environmental and Engineering Geophysics, Prague, Czech Republic, 31 August-4 September 2003, O-052, 4p.
Loke, M.H. and Barker, R.D. (1996) Rapid least-squares inversion of apparent resistivity pseudosections by a quasi-Newton method, Geophysical Prospecting, 44(1), 131-152.

MacDonald, D. (1970) The Development of Railway Borehole Water Supplies on the Bulawayo-Dette Section since 1950, The Rhodesia Science News, 4(12), 398-406.

Oldenburg, D.W. and Li, Y. (1994) Inversion of induced polarization data, Geophysics, 59, 1327-1341.

Overmeeren, R.A. van and Ritsema, I.L. (1988) Continuous vertical electrical sounding, First Break, 6(10), 313-324.

Svensson, M., Leroux, V. and Dahlin, T. (2004) Geoelektriska metoder för karakterisering av befintligt täckmaterial på deponi inför avslutningsplan, Procs. NGM 2004, Ystad, Sweden, 18-20 May 2004, 14p.

Tsourlos, P. (1995) Modelling, Interpretation and Inversion of Multielectrode Resistivity Survey Data, Doctorate thesis, Dept. of Electronics, University of York, $315 p$. 